\title{
Minimally Invasive
}

Technologies for the Treatment of Hypertrophic Scars

and Keloids: Intralesional

\section{Cryosurgery}

Yaron Har-Shai and Lior Har-Shai

\section{Contents}

\subsection{Background - 236}

28.2 The Technology: Treatment

Technique - CryoShape $[5,10]-236$

28.3 When to Use Contact or Intralesional Cryosurgery? - 237

28.4 How Many Cryosessions Are Needed for Contact or Intralesional Cryosurgery? - 239

28.5 Combined Treatment - 239

28.6 Conclusion - $\mathbf{2 3 9}$

References -240 


\subsection{Background}

A total of 100 million patients develop scars in the developed world alone each year as a result of 55 million elective operations and 25 million operations after trauma. Excessive scars form as a result of aberrations of physiologic wound healing and may develop following any insult to the deep dermis, including burn injury, lacerations, abrasions, surgery, piercings, and vaccinations. By causing pruritus, pain, and contractures, excessive scarring can dramatically affect a patient's quality of life, both physically and psychologically. Spray or contact cryosurgery is a nonsurgical therapy for the treatment of hypertrophic scars and keloids.

Cryosurgery is an effective and safe therapeutic regimen in the treatment of hypertrophic scars and keloids. Because of its major advantage of a low relapse rate, the technique, either as monotherapy or in combination, has been established as the treatment of choice for keloids and hypertrophic scars.

The cryosurgery freezing process includes four phases, which are termed "Thermal history." These phases include cooling rate, end temperature, hold time, and thawing rate. Each of these phases has an impact on the mechanism of injury on the frozen tissue. The tissue injury is induced by two synergistic arms - direct physical effects of cells freezing (intracellular ice formation) and by the vascular stasis that develops in the tissue after thawing. It is postulated that another factor in the effect on the tissue following cryosurgery is the immunologic response which is still under investigation.

Contact cryosurgery method uses metallic probes, which are circulated by a cryogen gas. This probe removes heat from the tissue and thus the tissue gradually cools. When the cryosurgical unit is activated and the probe is placed in firm contact with the tissue, an area of frozen tissue or ice ball appears, which extends radially from the cryoprobe. The lateral spread of freeze approximates the depth of freeze by a ratio of $1: 1.3$. Although the depth of freeze is time related, as the duration of freeze extends toward 100 seconds the lethal zone flats, that is, the deeper tissue is not affected. It has been shown that repeated contact cryosurgical sessions can exhibit a beneficial effect on keloids and hypertrophic scars and additionally prevent relapses. However, 1-20 treatment sessions using the contact cryosurgery were required to flatten those scars. In addition this method caused a high incidence of hypopigmentation. Therefore, the need for new, more potent, and quickly effective cryosurgical methods and instrumentation are warranted. Har-Shai et al. have developed the intralesional cryoneedle [1-15]. This technique exhibits an increased efficacy in the treatment of hypertrophic scars and keloids when compared with the contact method, due to the enhanced freezing area of deeply located scar tissue. In addition, fewer cryosurgical sessions are required, and less hypopigmentation is evident following the application of intralesional cryosurgery (• Fig. 28.1).

\subsection{The Technology: Treatment Technique - CryoShape [5, 10]}

With the patient lying at a supine position, the skin surface of the scar is cleansed with disinfecting solution and draped. The area of penetration into the scar and the underlying subcutaneous tissue are anesthetized locally, by a translesional approach, with Bupivacaine hydrochloride $0.5 \%$ (marcaine) [7]. Thereafter, the sterile cryoprobe (CryoShape, Life by Ice Ltd. Haifa, Israel) (- Fig. 28.2) is forced into the long axis, core, and midheight of the scar in a forward rotary movement, which is parallel to the skin surface. The scar itself is grasped between the index and thumb of the other hand, until the sharp tip of the needle penetrates the opposite distal edge of the scar, thus maximizing the volume of scar tissue to be frozen. Attention is taken to prevent any penetration of the cryoneedle into the healthy surrounding skin. Sterile gauzes are placed under the proximal and distal exposed parts of the cryoprobe and care is taken to assure that the vent nostril is positioned away from the patient to prevent accidental freezing of adjacent skin or tissue (- Fig. 28.3).

The proximal part of the probe is connected via an elongation tube to the cryogun (CryoPro Maxi $500 \mathrm{cc}$, Cortex Technology, Hadsund, Denmark), which is filled with liquid nitrogen to three-fourth of the cryogen volume and about 15 minutes beforehand in order to allow a sufficient pressure to build-up inside it (11 psi). A full pressurized cryogen can operate continuously for 1 hour, thus two to three medium-sized keloids can be treated successively without the need to refill.

The cryogun is grasped or placed on a steady surface, which is located higher than the scar to facilitate the liquid nitrogen flow downward with no direct contact with the patient body. By activating the cryogun trigger, the pressure valve is opened and the cryogen enters the cryoneedle, thereby freezing the scar. A forced steam of the liquid nitrogen gas flows out from the vent nostril during the entire freezing process. The strength of the steam flow, which is observed by the naked eye during the entire freezing procedure, indicates an appropriate working pressure. Two ice balls appear shortly at the two cryoprobe penetration sites of the treated scar and with time they gradually spread toward each other until a complete freezing of the scar is clinically evident. The 


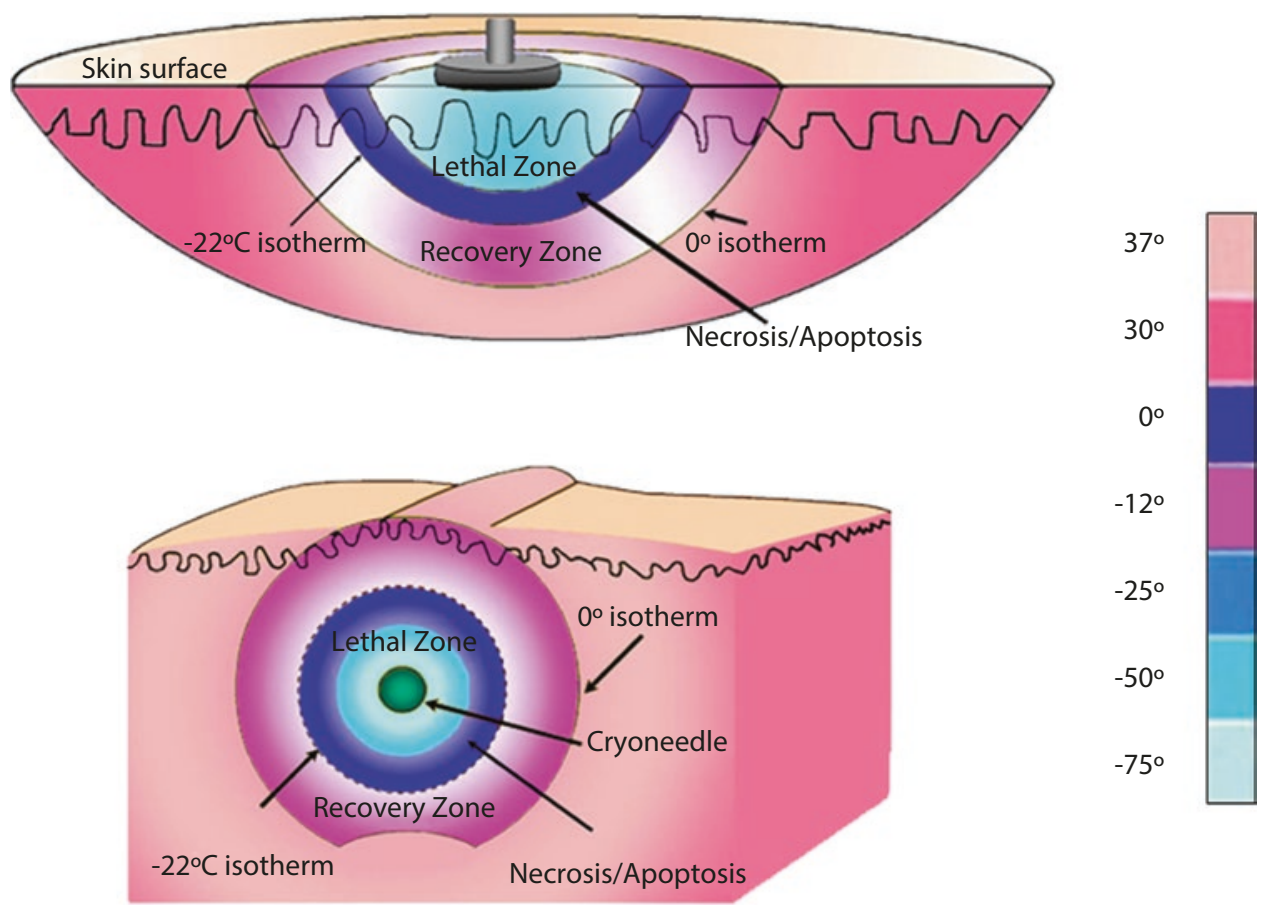

- Fig. 28.1 A comparison between the contact and intralesional cryosurgery methods. Upper - Contact method: Ice ball induced by the contact cryoprobe. The interface between the ice ball and unfrozen tissue represents $0{ }^{\circ} \mathrm{C}$ isotherm. The volume of tissue located between $-22{ }^{\circ} \mathrm{C}$ isotherm and contact probe is the lethal zone in which cells undergo cryonecrosis. Cells situated in the warmer region between $-22{ }^{\circ} \mathrm{C}$ isotherm and $0{ }^{\circ} \mathrm{C}$ isotherm (recovery zone) generally survive the freeze. The melanocytes are located within the lethal

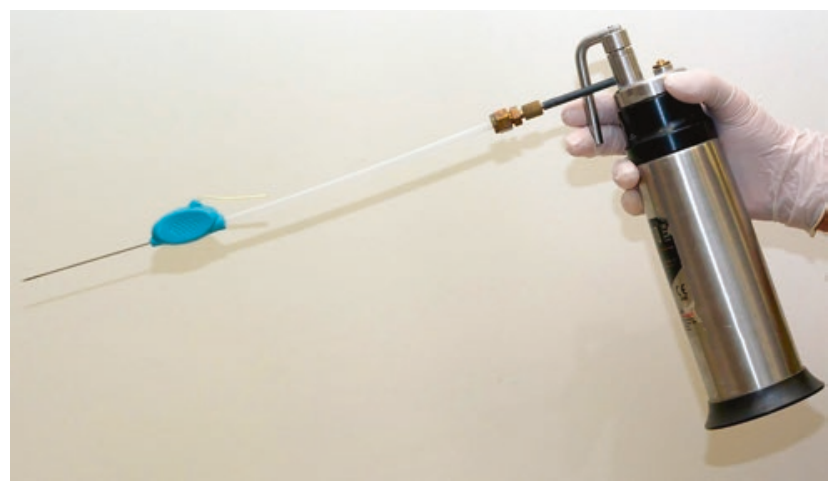

- Fig. 28.2 The intralesional cryosurgery system composed of the CryoShape cryoprobe which is connected to the cryogen

length of the intralesional cryosurgery process depends upon the scar volume and ranges between minutes to 3 hours without the need of time taking. Following the complete freezing of the scar, the cryogun trigger is released to stop the freezing process and the cryoneedle is left to thaw for $1-2$ minutes and is withdrawn in a reverse rotary movement. After a complete thawing of zone. Bottom - Intralesional method: Ice ball induced by the intralesional cryoneedle. The interface between the ice ball and unfrozen tissue represents $0{ }^{\circ} \mathrm{C}$ isotherm. The volume of tissue located between $-22{ }^{\circ} \mathrm{C}$ isotherm and cryoneedle probe is the lethal zone in which cells undergo cryonecrosis. Cells situated in the warmer region between $-22{ }^{\circ} \mathrm{C}$ isotherm and $0{ }^{\circ} \mathrm{C}$ isotherm (recovery zone) generally survive the freeze. The melanocytes are located within the recovery zone

the scar is clinically noticed, slight bleeding from the penetration points of the needle requires the application of a sterile dressing. If active bleeding is evident, gauzes soaked with Tranexamic Acid will end the bleeding. The patient is instructed to wash daily the treated scar and to apply an antibiotic ointment until full healing is accomplished.

In cases where the scar is longer than the cryoneedle length $(10 \mathrm{~cm})$ or very wide, two or three parallel needles or successive insertions of the same needle are necessary to freeze the entire keloid in one session.

\subsection{When to Use Contact or Intralesional Cryosurgery?}

Contact cryosurgery can be used on very small HSK with a reduced volume in which the cryoneedle cannot be inserted into. All other HSK can be treated by the intralesional cryosurgery method. In very large or giant HSK, several cryoneedles can be inserted in parallel to facilitate the freezing process. 

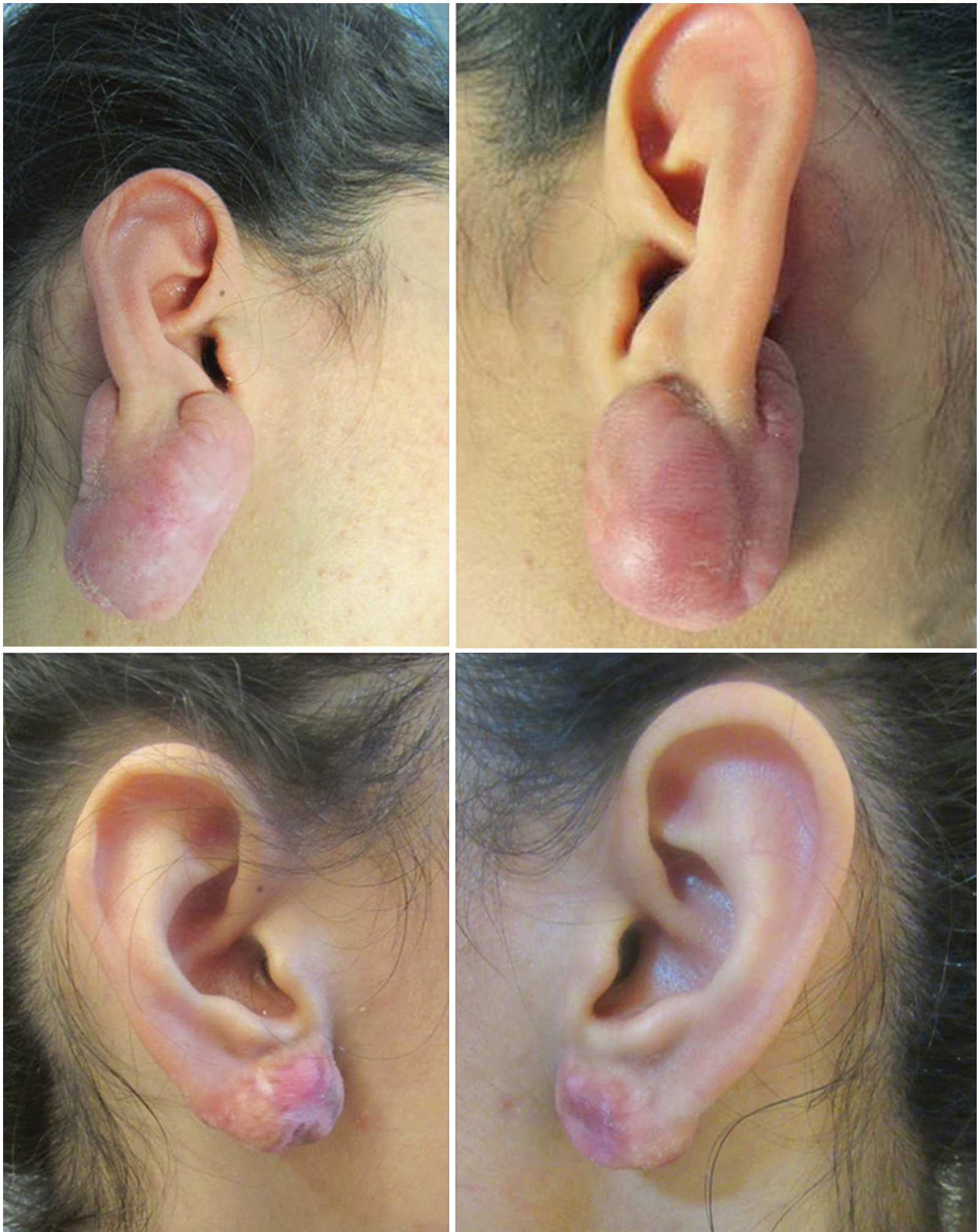

- Fig. 28.3 Upper - Preoperative view of two large keloids on the anterior and post aspects of the right and left lobules following

session of intralesional cryosurgery demonstrating complete involution of the scars with no distortion of the lobules and without piercing. Lower - Postoperative view 6 years following a single cryo-

hypopigmentation or recurrence 


\subsection{How Many Cryosessions Are Needed for Contact or Intralesional Cryosurgery?}

A total of 1-20 treatment sessions using the contact cryosurgery are required to flatten HSK scars. The interval between sessions is between 2 and 3 months.

For the intralesional method, usually a single cryosession is needed to flatten the HSK. In few cases a second cryo-treatment is needed. The interval between sessions is 6 months.

\subsection{Combined Treatment}

Intralesional cryosurgery can be combined with intralesional excision of the HSK [14], topical silicone gel sheeting [8], intralesional injection of steroids, and pressure garments. Following the flattening of the scars by cryosurgery, fractional $\mathrm{CO} 2$ lasers can be applied to further smoothen the skin surface if necessary [16].

\subsection{Conclusion}

This simple to operate technology can be applied as an office procedure, is safe, cost-effective, and possesses a short learning curve. This evidence-based novel intralesional cryosurgery method for the treatment of hypertrophic scars and keloids was recently intro-
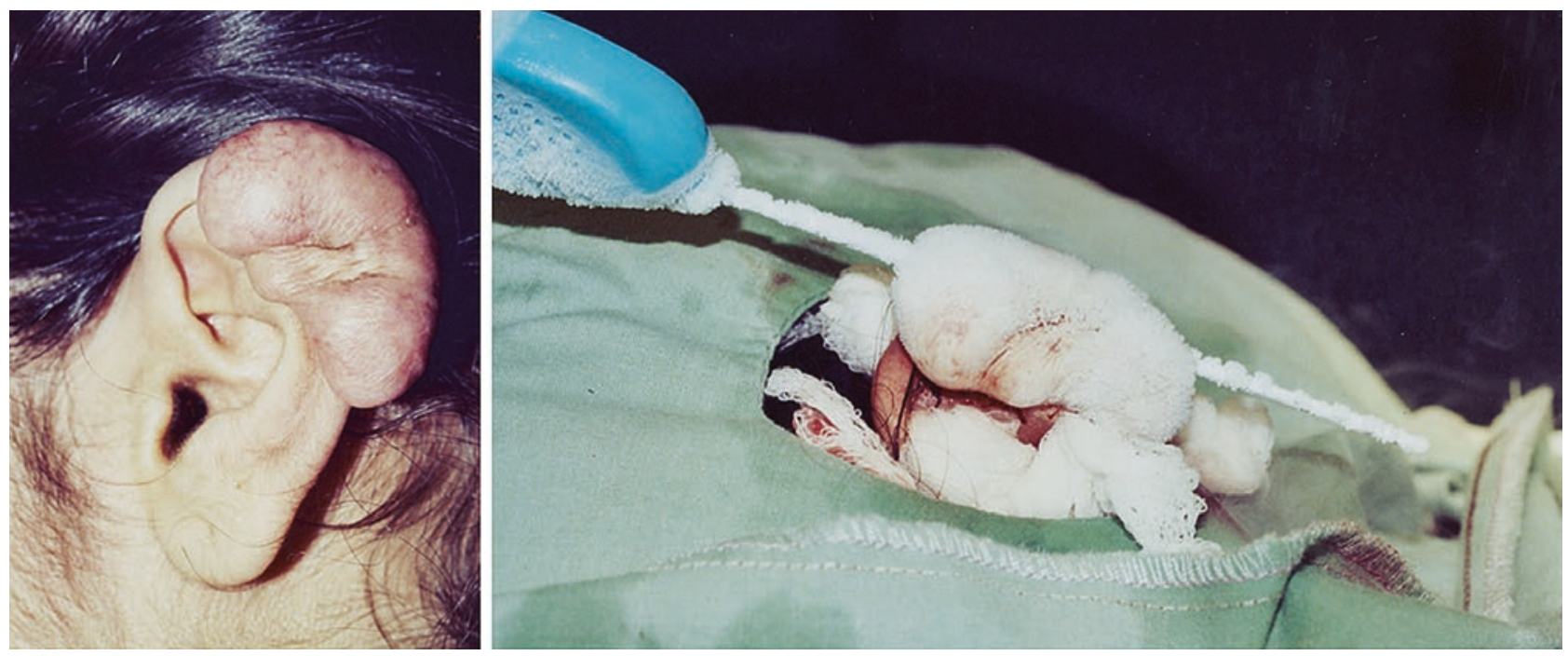
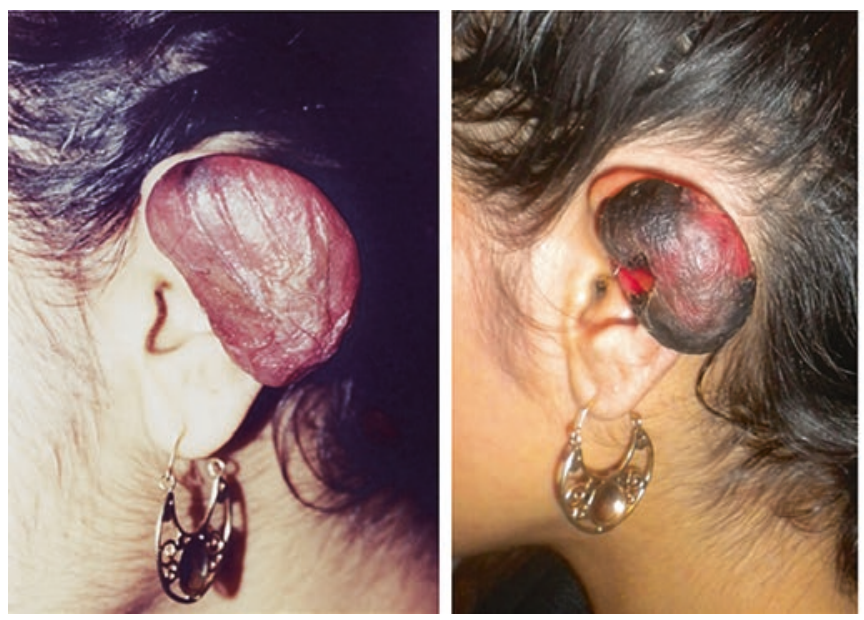

- Fig. 28.4 Sequential steps of the intralesional cryosurgery procedure and final result. Upper left - Preoperative view of a large keloid of the left upper ear following piercing. Upper right - Following penetration of the cryoneedle into the keloid, two ice balls are formed at the two penetration points of the scar. Warm gauzes are placed opposite to the treated scar (posterior aspect of the auricle) in order to prevent cryoinjury to the auricular cartilage. Lower left to lower
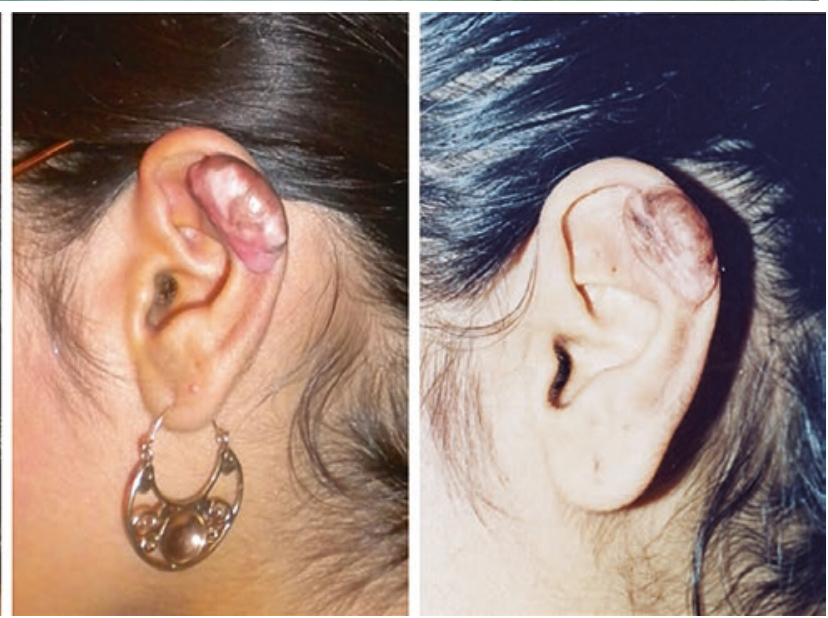

right - One week following the cryo-treatment a blister is evident; 3 weeks following treatment scar necrosis is evident; 6 months following the treatment the helical keloid has reduced significantly without distortion of the lobule and with almost no hypopigmentation; 4 years following a single cryosession, the scar is flat with some extra pliable skin above it which can be excised via an intralesional approach. No recurrence is evident 

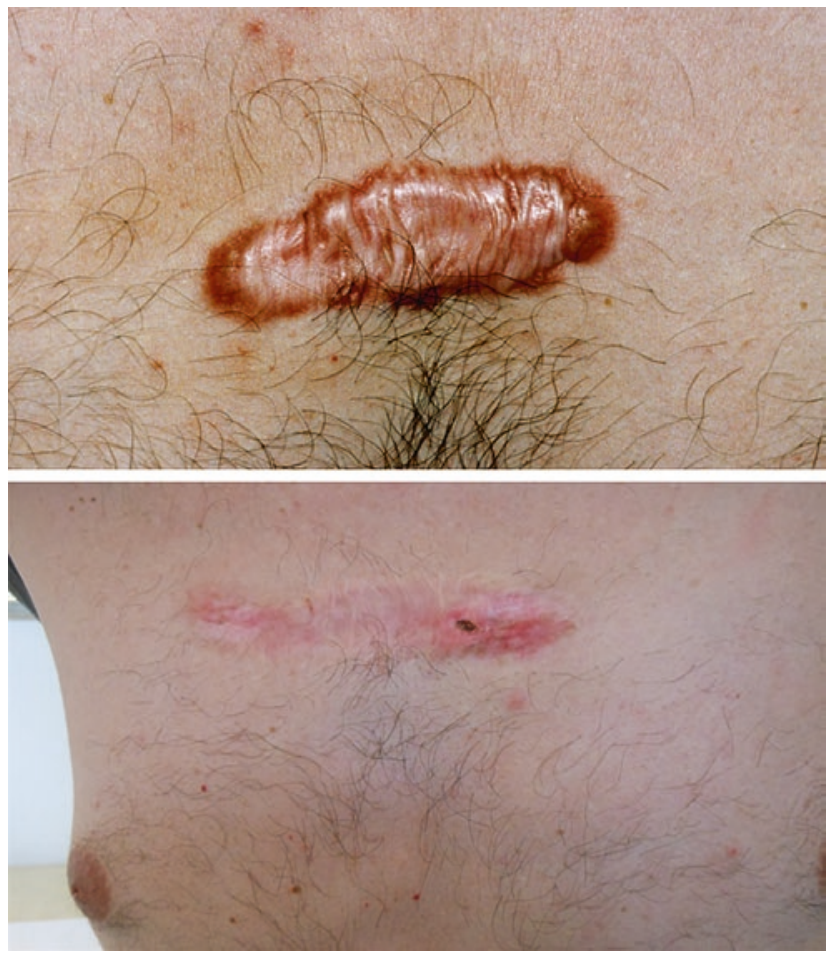

- Fig. 28.5 Upper - Preoperative view of a large keloid scar on the anterior chest following acne. Lower - Postoperative view demonstrating a complete flattening of the scar 10 years following a single cryosession with no recurrence or hypopigmentation

duced. This method was shown to be effective in the treatment of hypertrophic scars and keloids, and has achieved significant superior clinical results when compared with the existing treatment modalities (- Figs. 28.3, 28.4, and 28.5). In addition, it was demonstrated $[4,10]$ that this method has significantly reduced the patient concern and deformity scores in a scale from 1 (no concern and deformity) to 5 (severe concern and deformity) in 11 patients in whom keloids developed following aesthetic surgery. It was concluded that intralesional cryosurgery provides the plastic surgeon with an effective instrument to treat such scars following aesthetic surgery, thus reducing the dissatisfaction of patients.

The intralesional cryosurgery methods has two main advantages over the spray or contact cryosurgery techniques. Usually only a single cryosession in needed, and it exhibits significantly less hypopigmentation due to better survival environment for the melanocytes, thus can be effectively applied on black/darker-colored skin [1-3]. These beneficial advantages have an important clinical application for the treatment of hypertrophic scars and keloids especially on the face, which is the most crucial area of concern to the patient. Furthermore, the common treatment modalities which were mentioned to treat such a scar would necessitate several treatments and a long therapeutic period while the final results are unpredictable.

In summary, the intralesional cryosurgery technique might be added to the armamentarium of treatment modalities to effectively treat keloid scars. This method is easy to use, safe, can be applied on any size and shape of scars, requires a short learning curve, consumes less liquid nitrogen, and can be applied as an office procedure.

\section{Take-Home Message \\ Intralesional cryosurgery, which is an evidence-based method, is probably the best treatment for a variety of HSK (small, intermediate, large, and oversized) that achieves remarkable clinical results in a high proportion of patients with minimalhypopigmentation and usually by a single cryo-treatment.}

\section{References}

1. Har-Shai Y, Amar M, Sabo E. Intralesional cryotherapy for enhancing the involution of hypertrophic scars and keloids. Plast Reconstr Surg. 2003;111:1841-52.

2. Har-Shai Y, Sabo E, Rohde E, Hyams M, Assaf C, Zouboulis $\mathrm{CC}$. Intralesional cryosurgery enhances the involution of recalcitrant auricular keloids: a new clinical approach supported by experimental studies. Wound Repair Regen. 2006;14:18-27.

3. Har-Shai Y, Dujovny E, Rohde E, Zouboulis CC. Effect of skin surface temperature on skin pigmentation during contact and intralesional cryosurgery of keloids. J Eur Acad Dermatol Venereol. 2007;21:191-8. Erratum in: J Eur Acad Dermatol Venereol. 21:292, 2007.

4. Har-Shai Y, Brown W, Labbê D, Dompmartin A, Goldine I, Gil T, Mettanes I, Pallua N. Intralesional cryosurgery for the treatment of hypertrophic scars and keloid following aesthetic surgery: the results of a prospective observational study. Int J Low Extrem Wounds. 2008;7:169-75.

5. Har-Shai Y. Intralesional cryosurgery - a new and effective technology for the treatment of hypertrophic scars and keloids. Chapter II-10.1. In: Krupp S, Rennekampff H-O, Pallua N, editors. Plastische Chirurgie, Klinik und Praxis. Landsberg: Ecomed Medicin, Verlag Group; 2008. p. 1-7.

6. Har-Shai Y, Mettanes I, Genin O, Spector I, Pines M. Keloid histopathology after intralesional cryoneedle treatment. J Eur Acad Dermatol Veanerol. 2011;25(9):1027-36.

7. Mirmovich O, Gil T, Lavi I, Goldine I, Mettanes I, Har-Shai Y. Pain evaluation and control during and following the treatment of hypertrophic scars and keloids employing contact and intralesional cryosurgery - a preliminary study. J Eur Acad Dermatol Veanerol. 2012;26:440-7.

8. Stromps JP, Dunda S, Eppstein RJ, Babic D, Har-Shai Y, Pallua $\mathrm{N}$. Intralesional cryosurgery combined with topical silicone gel sheeting for the treatment of refractory keloids. Dermatol Surg. 2014;40:996-1003.

9. Chopinaud M, Pham A-D, Labbê D, Verneuil L, Gourio C, Benateau H, Dompmartin A. Intralesional cryosurgery to treat keloid scars: results from a retrospective study. Dermatology. 2014;229:263-70. 
10. Har-Shai Y, Har-Shai L. Intralesional cryosurgery for the treatment of upper lip keloid following deep chemical peeling. Eur J Plast Surg. 2014;37:679-82.

11. Har-Shai Y, Zouboulis CC. Intralesional cryosurgery for the treatment of hypertrophic scars and keloids. Chapter 86. In: Abramovich W, Graham G, Har-Shai Y, Strumia R, editors. Dermatological cryosurgery and cryotherapy. London: Springer; 2016. p. 453-74.

12. Roitman A, Luntz M, Har-Shai Y. Intralesional cryosurgery for the treatment of keloid scars following cochlear implant surgery and removal of cholesteatoma. Eur J Plast Surg. 2016;39:307-12.

13. O'boyle CP, Shayan-Arani H, Hamada MW. Intralesional cryotherapy for hypertrophic scars and keloids: a review. Scars Burn Heal. 2017;3:1-9.
14. Har-Shai L, Pallua N, Grasys I, Metanes I, Har-Shai Y. Intralesional excision combined with intralesional cryosurgery for the treatment of oversized and therapy-resistant keloids of the neck and ears. Eur J Plast Surg. 2018;41:233-8.

15. Zouboulis CC, Har-Shai Y, Orfanos CE. Cryosurgical treatment of keloids and hypertrophic scars. Chapter 85. In: Abramovich W, Graham G, Har-Shai Y, Strumia R, editors. Dermatological cryosurgery and cryotherapy. London: Springer; 2016. p. 413-51.

16. Har-Shai Y, Har-Shai L, Artzi O. Two-step treatment of bulky keloids on the cheeks after deep chemical peeling: intralesional cryosurgery followed by pulsed dye and ablative fractional $\mathrm{CO} 2$ laser. Eur J Plast Surg., published online 20 March, 2020. https://doi.org/10.1007/s00238-020-01651-x

Open Access This chapter is licensed under the terms of the Creative Commons Attribution 4.0 International License (http://creativecommons. org/licenses/by/4.0/), which permits use, sharing, adaptation, distribution and reproduction in any medium or format, as long as you give appropriate credit to the original author(s) and the source, provide a link to the Creative Commons license and indicate if changes were made.

The images or other third party material in this chapter are included in the chapter's Creative Commons license, unless indicated otherwise in a credit line to the material. If material is not included in the chapter's Creative Commons license and your intended use is not permitted by statutory regulation or exceeds the permitted use, you will need to obtain permission directly from the copyright holder. 